\section{STATE AID TO SCIENCE}

\section{UNDER this title the last number of the Lancet has} the following:-

It was for a long time the fashion with zealous workers in the field of science to protest that the cause of discovery would not be advantaged by State patronage or State aid. The more thoughtful inclined to the belief that the patronage would be more mischievous than the pecuniary assistance was helpful. For some years past this persuasion has been losing ground, and, whether scientists are becoming more worldly or less exclusive in their views, it is abundantly evident that the reverse of a feeling of unwillingness to accept aid from the State prevails. It will doubtless be contended that the way in which help has been placed at the disposal of explorers and investigators so completely removes all difficulties, that it would be not less ungracious than impolitic to refuse the proffered assistance. The labourer chooses his own form of enterprise, or applies for aid in the course of an inquiry instituted at his own wish, that he has simply to satisfy a committee of fellow-workers as to the object of his pursuit or the nature of his researches, and, upon their recommendation, the necessary funds are forthcoming, without the least semblance of dictation or interference. The explanation is obviously satisfactory, but the fact remains, the objections which many of the older and more successful discoverers urged against seeking or accepting the assistance of the State in their investigations have been discarded, and the only grievance felt by contemporary inquirers relates to what they conceive to be the paucity of the grant and its wrong distribution, for which last fault, if fault there be, the governing bodies of the principal scientific societies are mainly responsible. We offer no present opinion as to the comparative merits of the old and new view of the State aid question, and we do not propose to discuss the complaints arising out of the system of administration extant; it is for the more pressing issue, whether a permanent provision should no be made for the support of men who live by investigation rather than teaching, we now ask a few minutes' attention.

It must be conceded by all who have any acquaintance with the subject, that not only the pioneers, but, in a practical sense, the advanced workers in science must necessarily be debarred from the ordinary rewards of their profession. If it be difficult to practise and preach, it is incomparably more embarrassing to study and teach. In short, the explorers and investigators in any department of work cannot live by communicating the knowledge they accumulate. The business of utilising the store of information amassed by the labourers in the advanced field must be performed by men who are not themselves engrossed with research. The enterprise of discovery cannot be delayed while the explorers strive to popularise their acquisitions, nor are the faculties which prove most useful in the field of inquiry especially well adapted for successfully imparting the knowledge obtained. The functions of the scholar and the schoolmaster, the collector and distributor, are essentially different; we might go further and affirm that they are scarcely compatible. It follows, therefore, that the two classes of workers must always exist. Some must make knowledge and live by that form of labour, while others distribute or apply it to general uses. It seems to follow, without the need of argument, that by some expedient the means of self-support must be placed within reach of those who are not in a position to render their produce marketable. This necessity has been long recognised, and with a view to meet the case, College fellowships and snug sinecures in the Church and at Law have been preserved for the shelter and support of those who required scholarly leisure for the pursuit of inquiries. The spirit of the age is, however, eminently utilitarian and strongly opposed to sinecures; and, as a matter of fact, the system was manifestly open to abuses. The medical profession has never largely enjoyed these advantages, although the discoveries made by its members are equal, if they do not surpass, those of any other branch of labour in science. The time has come when the whole question needs to be discussed from a new standpoint, and in a more practical fashion than hitherto. We venture to suggest that it should not be left in the hands of interested persons who cannot speak freely on the topic, but considered by the profession as a body. The points to be adjudicated are: first, has medicine its full and fair share of State aid? and secondly, has not the time arrived when some formal provision should be made for the support of men who devote their lives to inquiry and cannot reasonably or expediently be expected to practise or teach? In the old days much of the hardest work in science was done by Churchmen of the various orders who were supported by the ecclesiastical institutions of the country; now the labour of research is performed by laymen, and they must live.

\section{THE TOURNAMENT OF INCUBATORS}

$\mathrm{T} N$ a recent number we referred to the hydro-incubator invented by Mr. Christy. This incubator, along with a number of others, has been subjected to a comparative trial at the Hemel Hempstead Waterworks. An account of this competition appears in the Live Stock Journal. It commenced 6 A.M. September 5, and concluded on September 26 , at 12 o' clock noon. The object of the committee who tested the incubation was-

(I) To ascertain whether incubators were of any practical value to the public generally; and

(2) If proved to be of value, to decide which was the best incubator for the ordinary purchaser to select.

That the person to whose management the incubators were entrusted should be unskilled and inexperienced in their use, was one of the conditions specially insisted on by the exhibitors. This was considered the best means of proving which incubator was of the simplest construction and could be worked most successfully without any previous apprenticeship. A large room in the Waterworks building was secured, where steam, hot water, or gas, could be employed, and where perfect privacy and quiet could be secured. Exhibitors were requested to send their incubators with full and clear instructions as to their method of working.

The eggs, which should be laid on Wednesday, September 4 , had been bespoken some time before at several farmhouses in the neighbourhood, and these having been collected during the afternoon of that day, were brought to the Waterworks, and thoroughly intermixed by the members of the committee. Each egg was then marked with the word "Couvense", by a stamp made at Brighton expressly for the occasion. By six o'clock on the morning of Thursday, September 5, the eggs had all been placed in the incubators by the members of the committee, the machines having been fully prepared for their reception. The incubators were then intrusted to the engineer, Mr. Twigg, with strict injunctions to follow implicitly the instructions of the exhibitors, and to admit no one without a written order from the committee to the room, which was to be kept locked, especially the exhibitors themselves or their agents. The following are the statistics of the competition itself, which were attached to the incubators as soon as possible after mid-day on September 26 :-

\section{No. I.-VoItellier: Hydro-Incubator.}

Of fifty eggs placed in incubator none were hatched.

This machine, from its simplicity and the ease with which the thermometer could be consulted, was quite a favourite with the engineer, who was most sanguine as to 
its results, and much disappointed at its failure. On subsequent examination no chickens were found in the eggs.

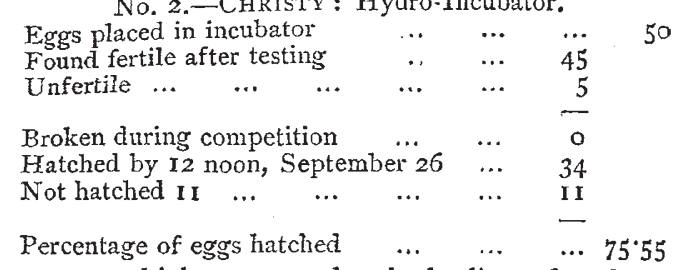

Three more chickens were hatched alive after the competition had closed. The other eggs, on being examined, were all found to have living chickens in them. The prize of $25 l$. was awarded to this incubator.

No. 3.-CHRISTY : Hydro-Incubator.

$\begin{array}{llll}\text { Eggs placed in incubator } & \ldots & \ldots & \ldots\end{array}$

$\begin{array}{lllll} & \cdots & \cdots & \cdots & \cdots\end{array}$

50

Broken during competition $\quad \ldots \quad \ldots \quad$ I

Hatched by 12 noon, September $26 \quad \ldots \quad 20$

$\begin{array}{llllll}\text { Not hatched } & \ldots & \ldots & \ldots & \ldots & 24\end{array}$

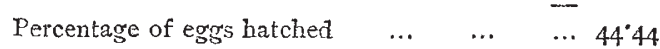

Two chickens were hatched alive after the competition was ended. Of the remaining eggs ten were found to have living chickens in them.

No. 4.--Boyle: Heated by lamp.

Eggs placed in incubator $\quad . . \quad \ldots$.

$\begin{array}{lllll}\text { Found fertile } \quad \ldots & \ldots & \ldots & \ldots & \\ \end{array}$

$\begin{array}{lllllr}\text { Unfertile } \ldots & \ldots & \ldots & \ldots & \ldots & 40 \\ \text { Unfer } & \ldots & \ldots & \ldots & \ldots & 3\end{array}$

\begin{tabular}{llll} 
Broken during competition & $\ldots$ & $\ldots$ & - \\
\hline
\end{tabular}

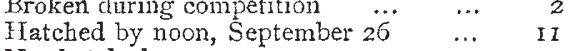

$\begin{array}{llllll}\text { Not hatched } \quad \ldots & \ldots & \ldots & \ldots & 27\end{array}$

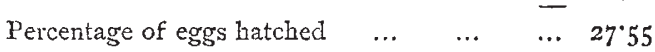

On examining the eggs, Saturday, September 28 , four chickens were found ready to break the shell. This incubator worked with great regularity, and deserves much commendation.

No. 5.-Boyle: Heated by gas.

Eggs placed in incubator

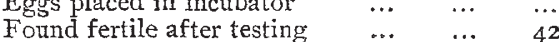

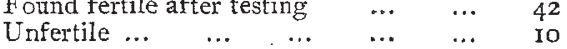

Broken during competition $\quad \ldots \quad \ldots \quad-\ldots$

Hatched by 12 o'clock noon, Sept. $26 \ldots$.

$\begin{array}{llllll}\text { Not hatched } \quad \ldots & \ldots & \ldots & \ldots & 16\end{array}$

Percentage of eggs hatched $\quad \ldots \quad \ldots \quad \ldots$

The egg rests in this machine are spiral wire springs The egg drawer did not fit well, and is certainly capable of improvement. Full and very clear instructions should always accompany this incubator. Its want of success must not be attributed altogether to the inexperience of the attendant.

No, 6.--Penman's (worked by lamp) : Exhibited by Messrs, E. T. Brown and Son, Newcastle-on-Tyne.

By this no eggs were hatched, but twenty dead chickens were found in the eggs on September 28 , having been dead apparently several days. The lamp in this incubator worked very irregularly, needing constant attention by day and night.

No. 7.-PENMAN's (worked by gas).

By this also no eggs were hatched, but on examining the eggs at 6 P.M. on Saturday evening, Sept. 28, thirty-four chickens were found to be alive in them, two having been hatched out on the same morning alive. The source of heat-viz., gas-had been turned off at 8 P.M. on the
Friday night previous, and the drawer had been opened. and shut constantly after the exhibition was opened at noon on Thursday. The irregularity of heat from the gas was doubtless the cause of failure in this instance, the pressure being very unequal.

The committee subjoin to this report a register of the temperature maintained in the drawer of each incubator, together with that of the water drawn off from the boilers in the case of the hydro-incubators. The chickens hatched are doing well, some under them, some in artificial mothers.

Such are the facts of this interesting trial, and they seem to us to prove not only that artificial incubation is possible, but that by Mr. Christy's machine, if not with some of the others, it might become a remunerative business, and add materially to the sources of our food supplies.

\section{NOTES}

By the kindness of Gen. Myer, the distinguished head of the U.S. Army Signal Service, we are enabled this week to give the official description of the weather case, the distribution of which among the 27,000 rural post-offices in the United States has just commenced. It is for use in those parts of the country where the daily weather indications cannot reach in time to facilitate agricultural operations, and its issue has been forced upon the Government because the American formers are wise enough to see that for them, as well as for sailors, to be forewarned is to be forearmed. In a few centuries we may expect to have something of the same kind here.

M. BoUIllaud, the once celebrated medical practitioner, who is a member of the Paris Academy of Sciences, assailed $M$. du Moncel in the sitting of September 30 , and asserted that the phonograph and microphone experiments must be the work of ventriloquists. This fit of incredulity was occasioned by the recital of experiments made with the singing conductors. M. du Moncel asked for a commission of investigation to be appointed, although such accusations are not deserving of any notice, and have, indeed, raised universal ridicule. But the regu-. lations of the Academy forbid any commission to be appointed to pronounce on the works or communications of members. Another curious scene took place at the sitting of last Monday. M. du Moncel presented to his colleagues, the "condensateur chantant," which had been exhibited on the previous Saturday. He retired to the room of the Académie Française, in company with $M$. Faye, closed the door and sang. His voice was heard coming from a number of sheets of paper, in which six sheets of tinfoil had been inserted, and connected with the wires of an induction coil. M. Bonillaud was obliged to retreat from the position he had taken at the sitting of September 3o. $\mathrm{He}$ made no allusion to the accusation of ventriloquism, but read a long quotation from Descartes, to show that "even if a speaking machine had been constructed, it could by no means be considered as a thinking machine." He said that speaking was not only a mechanical action, but also an intellectual work, so that neither the phonograph nor the singing condenser conld be regarded by any means as really speaking! The whole assembiy, in spite of its usual gravity, burst into roars of laughter. $M$. Milne-Edwards, who spoke at the previous sititng, said with much propriety, he should not have answered $M$. Bouillaud if he had understood such was his issue. Unfortunately he had usderstood, as everybody in the assembly did, that $M$. Bouillaufl questioned the honesty of the experimenter. At the end of the sitting M. du Moncel performed all the principal experiments of the phonograph.

SOME remarkable experiments in Electric Telephony were shown by Prof. Barrett in a lecture at the Midland Institute a 